\title{
Vacuum Picking of Nonwoven Material
}

\author{
Cubric G* and Ivandija A \\ Faculty of textile technology, University of Zagreb, Department of clothing technology, Croatia
}

Submission: January 26, 2018; Published: February 19, 2018

*Corresponding author: Cubric G, Faculty of textile technology, University of Zagreb, Prilaz baruna Filipovica 28a, 10000 Zagreb, Croatia, Email: goran.cubric@ttf.hr

\begin{abstract}
The complete automation of the garment manufacturing process is still present at certain times due to the nature of textile materials. Textile materials are flat, and this lack of stiffness affects the transfer of textile materials from one workstation to another in automated processes. With regard to the construction and the principle of operation, the grips are limited to certain types of materials and several processes they can perform. In the capture processes, the optimum handle has to be handled with different sizes and shapes of fabric, different properties and with one or more layers of material. Therefore, many researches are focused on designing handlebars for handling textile materials as well as the ability to capture them.
\end{abstract}

Keywords: Pneumatic; Grippers; Nonwoven material; Automation

\section{Introduction}

\section{Handling of textile materials and work pieces}

In textile and clothing manufacturing processes, we encounter problems in transporting materials and/or work pieces, their positioning, folding and stacking one at another. Problems occur due to the characteristic properties of the material. Since the textile material is not a solid material, it changes its shape due to any effect on it, such as when moving from one working place to another. Different transport devices solve material moving on a flat surface. An example are automated machine that moves the work piece directly on a flat surface or automate that guides the movement of the material through the guides.

The current industrial manipulators should be capable of manipulating loose materials. It is known that a small force also affects deformation and handling of textile material. During handling, the textile material can be folded, buckled or wrinkled. In addition, a large variety of fabrics, types, shapes and characteristics increase the severity of introducing flexible automation in the clothing industry [1]. The characteristics and properties of fabrics that have to be considered for successful performance of textile materials handling, and therefore the efficiency of the grippers are: thickness, low rigidity, bandwidth, elasticity, capability of retaining the charge, low mass, adhesion force. The effective gripper should be able to handle different sizes and shapes of fabrics, with varying properties and with one or more layers of fabric. With the ability to handle it, it is also necessary to ensure the safe transport of fabrics from one job to another $[2,3]$. The analysis of grippers in the textile industry has shown that, according to the principle of capture, they can be divided into five groups: mechanical, pneumatic, adhesion (adhesion), electrostatic and magnetic [4]. Several different principles for capturing and separating the parts can be applied in the same clamps, to increase the reliability of the textile hold. Mechanical grippers are most popular in the textile industry due to their simple construction and reliability [5-7]. Beside mechanical grippers, pneumatic grippers can be used in textile and clothing industry.

\section{Experiment}

Table 1: Characteristics of the nonwovens material.

\begin{tabular}{|c|c|c|c|c|}
\hline SAMPLE & $\begin{array}{c}\text { Sample } \\
\text { thickness } \\
\mathbf{m m}\end{array}$ & $\begin{array}{c}\text { Standard } \\
\text { deviation }\end{array}$ & $\begin{array}{c}\text { CV } \\
\mathbf{\%}\end{array}$ & $\begin{array}{c}\text { Sample } \\
\mathbf{m a s s} \\
\mathbf{g} / \mathbf{m}^{\mathbf{2}}\end{array}$ \\
\hline S1 & 1.178 & 0.07563 & 6.42 & 183.43 \\
\hline S2 & 4.384 & 0.13867 & 3.16 & 331.22 \\
\hline S3 & 1.26 & 0.06403 & 5.08 & 276.02 \\
\hline S4 & 0.26 & 0.00707 & 2.72 & 46.7 \\
\hline S5 & 0.21 & 0.00707 & 3.37 & 40.59 \\
\hline S6 & 0.964 & 0.0305 & 3.16 & 122.83 \\
\hline S7 & 0.316 & 0.02074 & 6.56 & 46.28 \\
\hline S8 & 0.346 & 0.00894 & 2.58 & 62.43 \\
\hline S9 & 1.768 & 0.03271 & 1.85 & 89.01 \\
\hline S10 & 0.238 & 0.02168 & 9.11 & 34.14 \\
\hline
\end{tabular}


The aim of this paper was to investigate the picking of nonwovens by vacuum grippers at input pressures of 4 to 6bar. For the experiment, we used 10 different samples of nonwoven textile materials cut into dimensions of $10 \times 10 \mathrm{~cm}$. Before we begin with the experimental part of the capture of the samples, we have to determine some basic characteristics of the nonwovens material that affect the ability to capture such as the thickness and the sample mass (Table 1).
After determining the properties of the material, we started by picking samples using vacuum grippers. The equipment we used for the measurement consists of a digital pressure gauge, air preparation unit, compressor, pressure regulator, pressure sensor, ejector and vacuum gripper (Figure 1a). We used 3 types of vacuum gripper: small circle (G1), large circle (G2) and flat (G3) (Figure 1b) [8].

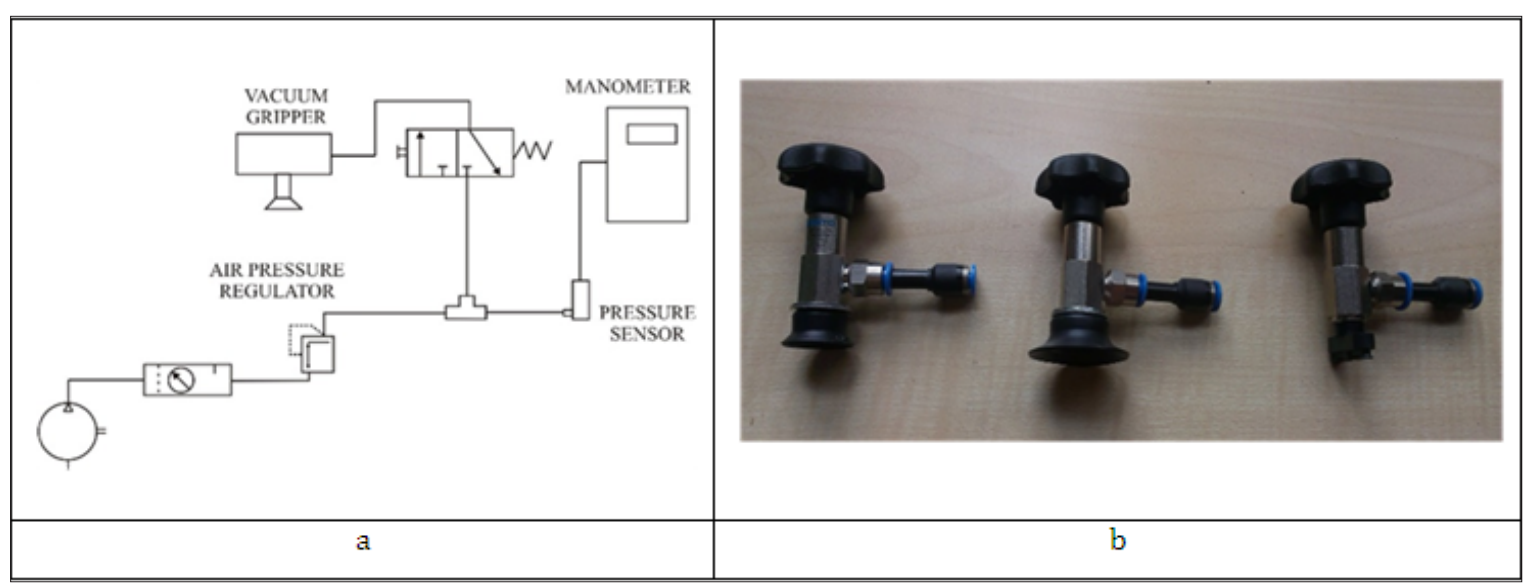

Figure 1: Display of measuring equipment, a. Schematic display of measuring equipment, b. Vacuum grippers.

The sample was placed on a flat surface and a vacuum gripper in the middle of the sample. By using a digital pressure gauge, we changed the inlet pressure entering into the ejector from 4 to 6bar. We observed whether at a given input pressure the sample was raised to a height of $15 \mathrm{~cm}$ (Figure 2).

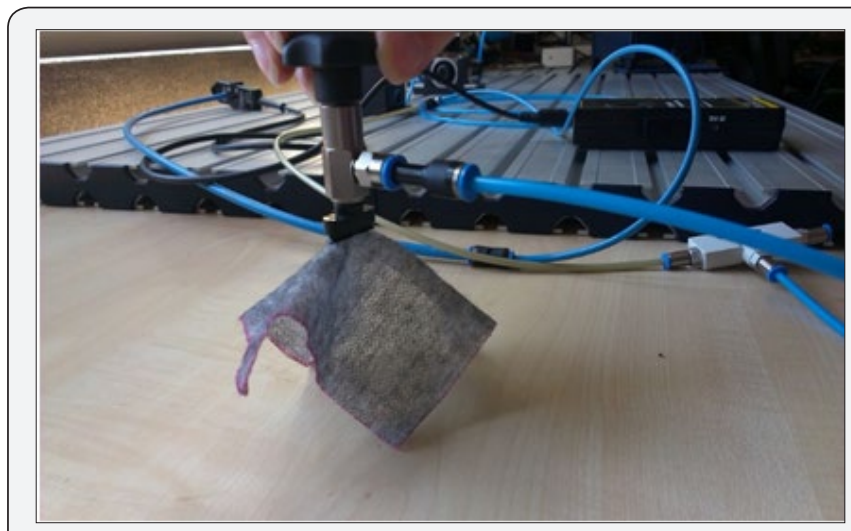

Figure 2: Picking of the sample with a vacuum gripper [8].

\section{Results and Discussion}

From Table 1 can be seen that we had a wide range of nonwoven material. The sample thickness is $0.21-4.384 \mathrm{~mm}$ and the mass of $34.14-331.22 \mathrm{~g} / \mathrm{m}^{2}$.

Table 2 shows the results of picking nonwovens materials by of 3 tips of vacuum grippers (small circle G1, large circle G2 and flat G3) at pressures of 4 to 6bars. Mark A indicates that sample was not been accepted, label B that sample was accept and held and the mark $\mathrm{C}$ that griper was during measurement of the sticks to the surface.
Table 2: Results of picking the samples by vacuum grippers.

\begin{tabular}{|c|c|c|c|c|c|c|c|c|c|}
\hline & \multicolumn{3}{|c|}{ Gripper 1} & \multicolumn{3}{|c|}{ Gripper 2} & \multicolumn{3}{|c|}{ Gripper 3} \\
\hline ssure [bar] & 4 & 5 & 6 & 4 & 5 & 6 & 4 & 5 & 6 \\
\hline S1 & A & A & A & $\mathrm{A}$ & A & A & A & A & A \\
\hline $\mathrm{S} 2$ & $\mathrm{~A}$ & A & A & A & A & A & A & A & A \\
\hline S3 & A & A & A & A & A & A & A & A & A \\
\hline S4 & A & A & A & A & A & C & A & A & A \\
\hline S5 & A & $\mathrm{C}$ & $\mathrm{C}$ & $\mathrm{C}$ & $\mathrm{C}$ & C & B & B & B \\
\hline S6 & A & A & A & A & A & A & A & A & A \\
\hline S7 & A & A & A & $\mathrm{A}$ & A & A & A & A & A \\
\hline S8 & A & A & A & A & A & A & A & B & B \\
\hline S9 & A & A & A & A & A & A & B & B & B \\
\hline S10 & A & $\mathrm{C}$ & $\mathrm{C}$ & $\mathrm{A}$ & A & A & B & B & B \\
\hline
\end{tabular}

As can be seen from (Table 2), with gripper 1 (H1) could not catch a single sample. At the inlet pressure of 5 and $6 \mathrm{bar}$, the 55 and S10 the gripper is sticks to the surface. Both samples have a mass less than $41 \mathrm{~g} / \mathrm{m} 2$ and thickness less than $0.24 \mathrm{~mm}$. With gripper 2 (H2) the situation is almost identical. No sample has caught with this gripper. The only difference is at sample S10 where the gripper does not stick to the substrate. This can be assign to the larger surface of the rubber part of the gripper. By gripper 3 
(H3) we have completely different results. With this gripper, we managed to capture four samples (S5, S8, S9, S10). Samples S5, S9 and S10 were captured with all three inlet pressures, while sample 88 was not caught at a minimum pressure of 4 bar. Sample S2 is interesting. It has the highest mass of all tested samples $(331.22 \mathrm{~g} / \mathrm{m} 2)$ and the largest thickness $(4.383 \mathrm{~mm})$, but could not be lift with any gripper. This tells us that to determine what characteristics should have nonwovens to catch it with a vacuum gripper, we need to find another characteristic beside mass and thickness.

\section{Conclusion}

In textile and clothing manufacturing processes, a great deal of time goes to handling and manipulating materials and work pieces. Problems occur due to the characteristic properties of the material. Therefore, production time is much longer than in other industries where harder materials are used. The simplest way to reduce the making time is the automatic handling of materials applying vacuum gripper. Considering the results of experiments conducted with vacuum grippers, further tests should carried out with including other characteristics of the material.

\section{References}

1. Kondratas A (2005) Robotic Gripping Device for Garment Handling Operations and Its Adaptive Control. FIBRES \& TEXTILES in Eastern Europe 13(4): 84-89.

2. Cubric G (2015) The principles of textile material automatic. TEDI 5(5): 99-103.

3. Jiménez-Schlegl P, Cubric G (2018) Robots in the Textile and Fashion Industries: Facts and prospectives, $11^{\text {th }}$ Scientific-professional symposium textile science and economy, Zagreb, Croatia.

4. Nikolic G, Katalinic B, Rogale D, Jerbic B, Cubric G (2008) Robots and use in textile and clothing industry, Zrinski, Čakovec, Croatia.

5. Doulgeri Z, Fahantidis N (2002) Picking up flexible pieces out of a bundle. IEEE Robotics \& Automation Magazine p. 9-19.

6. Ono E, Kitagaki K, Kakikura M (2005) On Friction Picking Up a Piece of Fabric from Layers. Proceedings of the IEEE International Conference on Mechatronics \& Automation Niagara Falls, Canada.

7. Shibata M, Ota T, Endo Y, Hirai S (2008) Handling of Hemmed Fabrics by a Single-Armed Robot. 4th IEEE Conference on Automation Science and Engineering Key Bridge Marriott, Washington DC, USA, p. 23-26.

8. Ivandija A (2017) Capturing nonwoven textiles with different pneumatic grippers, final work, Zagreb, Croatia.

\begin{tabular}{|l|}
\hline \multicolumn{1}{|c|}{ Your next submission with Juniper Publishers } \\
will reach you the below assets \\
- Quality Editorial service \\
- Swift Peer Review \\
- Reprints availability \\
- E-prints Service \\
- Manuscript Podcast for convenient understanding \\
- Global attainment for your research \\
- Manuscript accessibility in different formats \\
( Pdf, E-pub, Full Text, Audio) \\
- Unceasing customer service \\
Track the below URL for one-step submission \\
https://juniperpublishers.com/online-submission.php \\
\hline
\end{tabular}

